\title{
Ownership Reform of On-duty Inventions and University Patent Output: Analytical Model and Empirical Evidence
}

\author{
Guang Chen, Xin Liu* \\ School of Public Affairs and Law, Southwest Jiaotong University, Chengdu 610031, China
}

\begin{abstract}
Based on a literature review, this article reveals the inconsistency in the ownership structure reform measures of on-duty inventions, a policy attempt to stimulate patent output and commercialization. It also proposes an analytical model to address the impact of intellectual property ownership structure on patent productivity. A total of 20 universities with two different kinds of intellectual property ownership structures in Sichuan Province of China are selected for this study. They are divided into two groups: "pilot group" and "control group". The quantitative statistics and comparison of development trends and changes in the number, structure, technical fields, transfer and quality of invention patents are conducted, showing the development status of university patents before and after the ownership reform, and verifying the impact of the ownership structure of on-duty inventions on stimulating patent output. For a deep understanding of the situation, Southwest Jiaotong University is taken as a typical case for the study, which illustrates that after the implementation of the ownership reform, the number of disclosures of patent achievements of university on-duty inventions has increased, and the patent transformation in universities has undergone positive changes, but the positive changes in patent quality between universities are not obvious in the short term. In addition, this article puts forward countermeasures and suggestions for further optimization of the reform, with a view to achieve the staged evaluation of the reform and guiding practice. Finally, the article endeavors to provide academic peers with Chinese policy experiments and data regarding the impact of intellectual property ownership structure on invention output.
\end{abstract}

\section{Keywords}

on-duty inventions; ownership reform; universities; patents

\footnotetext{
" Corresponding author at: School of Public Affairs and Law, Southwest Jiaotong University, Chengdu 610031, China

E-mail address: liuxin_hust@foxmail.com
} 


\section{Introduction}

The impact of intellectual property (IP) ownership and structural changes on the output and operation of on-duty inventions has always been one of the concerns to academics and policy circles. Over the past four decades, various regions and countries in the world have carried out reforms related to the ownership of on-duty inventions at different levels. The Bayh Dole Act of 1980 allowed U.S universities to hold IP rights in federally funded research inventions, while requiring researchers to disclose their research results to the Technology Licensing Office (TLO) of universities (Mowery, 2004), thereby significantly promoting the commercialization and spread of universities' research results. The Bayh Dole Act greatly increased the number of patent applications and commercialization in American universities in the 1980s and 1990s. However, the number of patent applications in various universities in the United States gradually decreased around the year 2000. Some scholars believe that this phenomenon occurs because the institutional advantages of the Bayh Dole Act as an incentive mechanism have been exploited to the full in the phenomenon of "end of utility" (Meyer, 2010).

By drawing on the experience of the Bayh Dole Act implemented in the United States, European governments have widely promoted a policy of ownership of on-duty inventions based on institutional ownership. In general, the ownership of on-duty inventions consists of three types: state ownership, unit or institution ownership, and employee ownership. The United States clearly stipulates that the employee inventor must apply for a patent and then transfer the on-duty invention ownership to the institution. In Europe, "Professor Privilege" prevailed in Germanic-speaking countries. This form of ownership allows university professors to hold patents and utility model rights of their research results; if a scientist is employed by a public research laboratory or a private company, the inventions belong to themselves by default (Lissoni, 2015). Affected by the successful stories of American universities in business innovation, many European countries enacted laws favoring "university ownership" around 2000. For example, countries like Germany, Austria, Denmark, Finland, and Norway amended their laws to end "professor privilege". Sweden is one of the few countries that are still implementing the "professor privilege" system. The ownership of on-duty inventions in universities is internationally diverse. Countries such as Norway and Germany that renounced the "professor privilege" system have experienced significant reductions in university patent disclosure and achievement transfer right after the reform, which has led to much introspection. Studies have shown that, whether it is "university-owned" or "professor privilege", the empirical research conclusions do not have "consistency".

In China, the exploration of the "mixed-ownership" (which means an IP is jointly owned by the employee and the employer) reform of on-duty inventions, including "employee ownership" in universities, started at Southwest Jiaotong University in 2010. In the following ten years, this reform has gone from "new rules for research institutions" and "local government policies" to "National Promotion Pilot". In 2016, Sichuan province was the first to carry out the reform of the intellectual property ownership and benefit-sharing system for onduty inventions in 20 universities and research institutes. The expectation of the reform is to divide and reconfirm the ownership of on-duty invention patents so as to help achieve the economic and business aims of technology innovation. Because of the complexity of the relationship between technology and market, and the institutional context dependence of on-duty inventions, the research on the relationship between "ownership of on-duty inventions" and patent output (quantity and quality) has become an academic issue with practical value. Scholars can't help asking questions such as: With "ownership of on-duty inventions" as an explanatory variable while patent output (quantity and quality) as an explained variable, has the policy design of the mixed ownership reform of university on-duty inventions achieved its expected policy effects? What are the trends in the number, 
structure, technical fields, transfer, and quality of university patents before and after the reform? What policy implications will the early stage reform measures bring to the further reform of the ownership of on-duty inventions? The relationship between the reform and patent output of universities needs to be investigated.

\section{Literature Review and Theoretical Models}

\subsection{Ownership of intellectual property and inconsistent innovation incentives}

The ownership policies of intellectual property greatly affect the process and direction of the transfer of university on-duty inventions, and different policies have various implications for the commercialization of academic inventions. On the one hand, under university ownership, scholars have come to different conclusions. For example, Crespi and Geuna (2010) used patent data from six European countries and found that the employee ownership of university patents reduced the efficiency of knowledge transfer. On the contrary, the commercialization rate of patents under university ownership is higher. However, some scholars believe that university ownership is not conducive to invention. For example, using forward citations, Lissoni et al. (2010) discovered, in fact, the universities patent ownership have lowered the quality of patents compared with enterprises and companies under same conditions in Denmark, France, Italy, the Netherlands, Sweden and other countries. Whether under university ownership or "professor privilege", the ultimate goal of system selection is to achieve effective innovation incentives, promote more high-quality inventions output and realize business value of invention. An opinion in favor of university ownership of intellectual property rights of on-duty inventions is mainly based on the employee inventor's own job and range of ability, arguing that universities are the main body of patent commercialization whereas the view preferring "professor privilege" is mainly from the perspective of achievement transfer motivation. Therefore, which system to choose and what kind of results it produces depend entirely on the starting point of policy formulation and the institutional environment of different countries.

On the other hand, under the "Professor Privilege" system context, scholars' research conclusions are always different. Kenney and Patton (2011) conducted an empirical test on the effect of different ownership systems to encourage the commercialization of on-duty inventions. They described and analyzed the data of scientific and technological invention ownership of the staff from 5 U.S. universities and 1 Canadian university. Their results of ownership verification and segmentation tests show that employee inventor ownership has a positive effect on entrepreneurial behavior, and the employee inventor ownership system has significantly created more monetary funds than university ownership. Ejermo and Källström (2016) studied the responsiveness of patent toward research and development activities in different disciplines of Swedish universities. They found that the responsiveness of Swedish universities is generally higher than that of the United States. Therefore, they discussed the impact of different ownerships on patent activities and academic entrepreneurship, believing that Swedish academic research contributed greatly to invention activities, and supporting the idea that professor privilege system is one of the contributing factors.

\subsection{Potential impact of the shifts in intellectual property rights ownership: a theoretical model}

Studies on the policy effects of on-duty invention ownership reforms have shown different empirical results in different countries: some research shows that changes in ownership policies have altered the rate of invention creation and commercialization. For example, Siegel and Veugelers (2007) used patent data from 1970 to 2006 to explore whether the US Bayh Dole Act, Technological Innovation Act and the 1986 Federal Science and Technology Transfer Act have promoted the patent increasing trend of federal laboratories by using 
econometric method. They found that the Technology Innovation Law significantly affected the patent trend, and the Federal Science and Technology Transfer Law promoted commercialization, thus provided employee inventors with external economic incentives. Other research shows that the ownership policy shift has impaired innovation and creation as well as academic entrepreneurship. For example, Hvide et al. (2018) compared university employee inventors with other employee inventors, and studied their behavior under the influence of reform policies. They found that the Norwegian policy reform transferred two-thirds of the income rights enjoyed by university researchers to universities, making the number of researchers at start-ups and universities drop significantly by about $50 \%$, and lowering the quality indicators of patents and the numbers of start-ups. However, some scholars believe that employee inventors' innovation and entrepreneurship activities are not affected by ownership, and the research on the implementation effect of the US Bayh Dole Act has not reached a more consistent conclusion. The above-mentioned research shows that the actual effect of university on-duty invention ownership shift is dependent on the institutional context, and it is necessary to empirically test the policy effect of the mixed ownership reform of on-duty invention ownership in combination with China's reform practice.

There are relatively few empirical studies on institution ownership in China since 2000. Existing studies such as Zhang Junrong and Yuan Xiaodong (2014) have examined the impact of the "Chinese version of Bayh Dole Act" on patent output, and found that the shift of "institution ownership" since 2000 has not promoted patent output in China's universities. Domestic studies of the transfer of on-duty inventions in universities are mostly centered on incremental comparison and pattern analysis. However, there are few empirical studies on the effects of various incentive policies such as the right to use, disposal, and income to promote the transfer of on-duty inventions, and there is no "ownership system" related research involved. Regarding the reform policy of university on-duty invention ownership, existing China's domestic researches have focused on the implementation logic, transfer mechanism, policy and law, and ownership issues, such as Chen Baiqiang (2017), Wu Shouren (2017), Cao Aihong (2018), but in general, the evaluation of the implementation effect of the different ownership structures of university on-duty inventions is still in its infancy.

Based on literature study, this article believes that there are two directions of shift in the ownership structure of intellectual property rights $(O)$ : "concentration" (rights toward employers) and "decentralization" (rights toward employees). Both "concentration" and "decentralization" have two directions of influence, patent $(P)$ (quantity/quality) increases or decreases, that is, positive and negative influences. The ideal state of patent system design is the process of finding a certain balance point $(v)$. It can be called the "bidirectional model of patent ownership structure", as shown in the Figure 1.

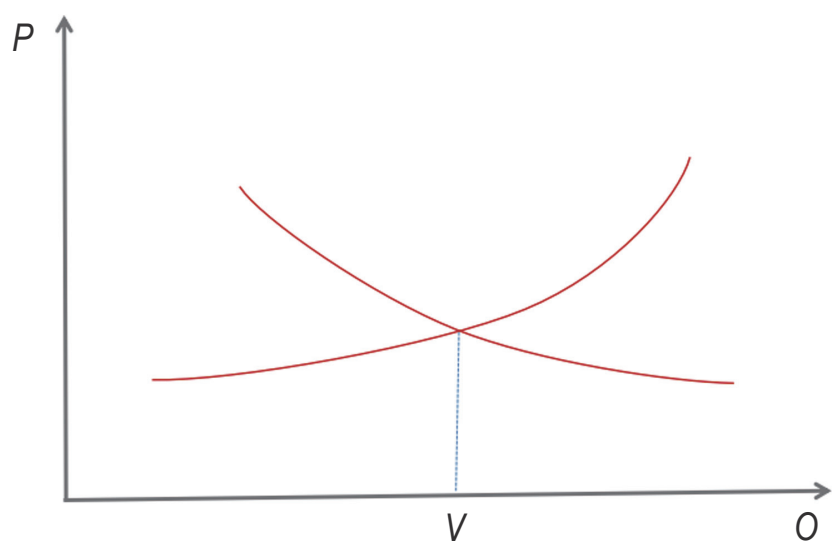

Fig. 1 Bidirectional model of ownership structure 
The quantity and quality of patents are "explained variables" $(P)$, and the ownership status of patents $(O)$ is an explanatory variable. So there is a theoretical model:

$$
P_{i t}=\beta_{o}+\beta_{1} O_{i t}+C_{j}+\S
$$

$i=1,2,3, \ldots$, represents the number of patents or patents of different quality; $t$ represents the year; $C$ represents the control variable, $j$ represents the number of control variables; $\S$ represents the residual; $\beta$ is the parameter.

The research direction of this article is to explore the changes in the quantity and quality of patents in the Chinese scenario, and the condition is that the ownership structure tends to be decentralized. Therefore, these are assumptions:

H1: "Mixed ownership" of patent rights has a positive impact on the number of patents (the number of patents includes disclosure and transfer quantity);

H2: "Mixed ownership" of patent rights has a positive impact on the quality of patents (patent quality in this research includes technical dimension and legal dimension).

\section{University Patent Development Under the On-duty Inventions Ownership Reform}

This article takes universities in Sichuan Province as the analysis objects. However, in view of the nature and function differences of each university, as well as the availability of patent data, only public universities in the province are selected as the samples for data collection. These samples are of representative of the universities in Sichuan Province in general. The data source of this analysis is Incopat patent database. In the process of data collection, we used the sample universities as the applicants to collect patent data with time range from 2008 to 2018. The study gleaned the information about a total number of 85,996 patent applications (industrial design patents were filtered) and the data about 37,961 invention patents (including patent applications and granted patents, meanwhile deleting duplicate patents that have been authorized in applications) in universities that have accomplished or didn't start a on-duty invention ownership reform. The data retrieval date is April 14, 2019, with a total of 89,311 pieces of data; the design patents were filtered out and 85,996 pieces of data were obtained.

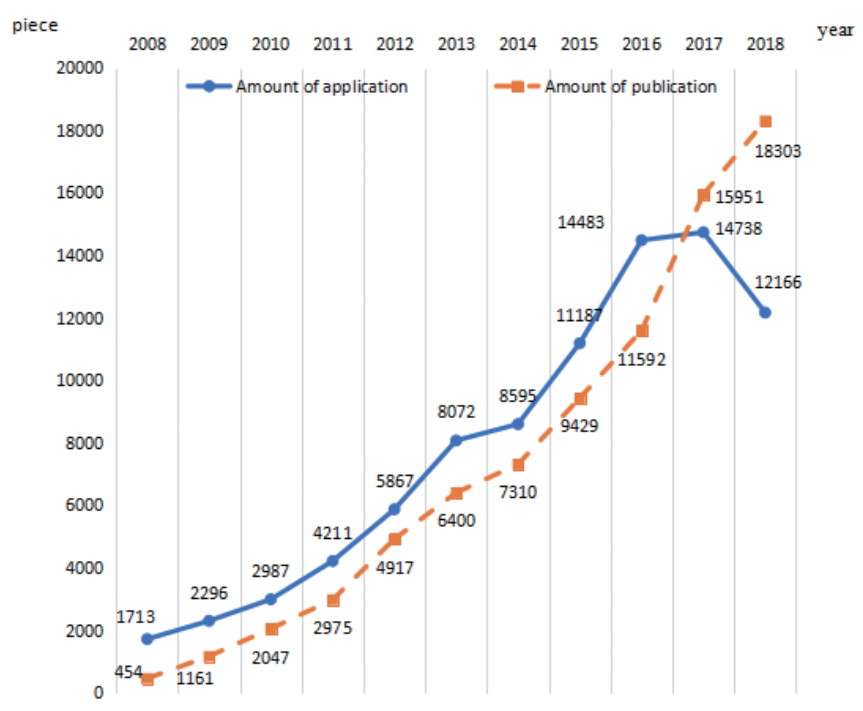

Fig. 2 Number of patent applications and publications of universities in Sichuan Province 


\subsection{The general trend of patent output of universities in Sichuan Province (2008-2018)}

\subsubsection{Number of patent applications and publications}

As shown in the Figure 2, the number of universities in Sichuan Province has grown significantly, and the number of patent publications (achievement disclosures) has increased year by year. From 2008 to $2018,89,311$ patents (including industrial design) ${ }^{1}$ have been applied for by universities in the province, and the number of patent applications and publications showed a parallel growth trend. The data shows that after 2016, however, their trend of patent application and publication number began to diverge. Their growth trend for the number of patent applications slowed in 2016, and the decreasing trend continued after reaching a peak of 14,738 in 2017 while the number of patent publications (disclosures) continued to show a linear growth pattern after 2016. Since 2015, the growth rate of the disclosure of existing scientific research achievements has accelerated. In 2017, patent publications outnumbered patent applications for the first time over past 10 years. The number of disclosures of patent achievements for on-duty inventions in universities in Sichuan Province has increased rapidly after 2016, and university employee inventors tended to disclose their patent related achievements to their employers with a more positive attitude.

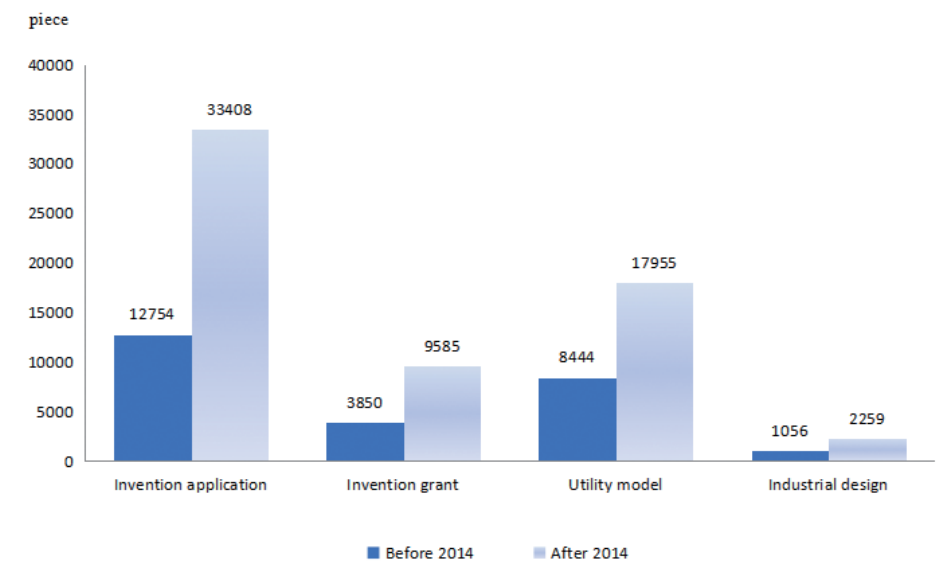

Fig. 3 Types of patents published by universities in Sichuan Province

\subsubsection{Patent type and technical structure}

a. Patent type and proportion

As Figure 3 shows that based on the comparison between the two stages in the past decade, it has been found that the number of invention patent applications, invention grants and utility model grants in universities in Sichuan Province has increased significantly. In another word, their high-quality innovation activities have been more vigorous. From 2014 to 2018, the number of invention patent applications and utility models was increased dramatically from the previous five years. The number of invention applications from 2014 to 2018 was 2.6 times that of 2008 to 2013, and the number of invention grants was 2.4 times, utility model and appearance design was 2.1 times. Invention patents embodied the highest degree of patent related achievements, which shows to a certain extent that their highquality innovation motivation over the past five years is getting stronger. In general, university patents applications are mainly focused on invention patents.

\footnotetext{
${ }^{1}$ General invention patents are published 3-18 months after application, utility model patents and design patents are published about 6 months after application. Some patents will not be published until 2019.
} 


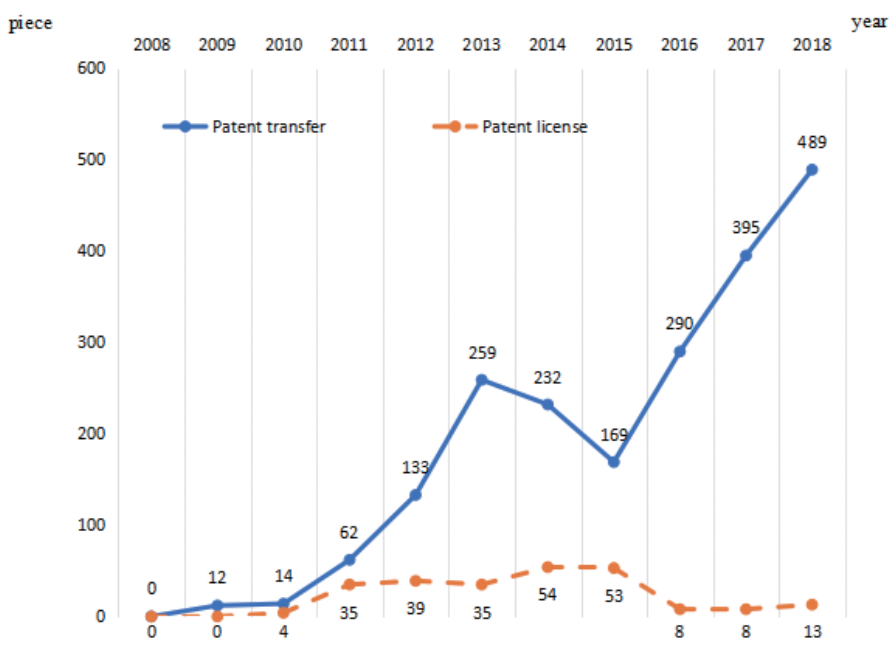

Fig. 4 Number of patent transfer and license in universities in Sichuan Province ${ }^{2}$

\section{b. Patent transfer trends}

In Figure 4, the data shows that after 2015, the number of transfer of the university on-duty inventions has increased significantly. Since 2015, the number of patent transfers in universities in Sichuan Province has soared, which was in line with the promulgation of China's newly revised Law on Promoting the Transformation of Scientific and Technological Achievements in 2015. In addition, Sichuan Province has issued a series of policies with a positive stimulating effect on university patent transfers; in contrast, the number of university patent license has been quite small for many years, and has shown a downward trend after 2015.

After 2015, the number of on-duty inventions transfer in Sichuan universities was significant, and pilot universities (those piloting the reform) were the main force for the transfer. Three universities directly under the Ministry of Education: University of Electronic Science and Technology, Southwest Jiaotong University and Sichuan University, have the largest number of patent transfer, accounting for $54.16 \%$ of the total in the past ten years. Among the top ten patent transfer performers, six were the universities piloting the mixed ownership reform of on-duty invention in the province, including Southwest Jiaotong University, Sichuan University, Sichuan Agricultural University, Chengdu University of Technology, Chengdu University and Southwest University of Science and Technology. Chengdu Southwest Jiaotong University Science and Technology Park Management Co., Ltd. is a school-run enterprise of Southwest Jiaotong University ${ }^{3}$. According to the trend of patent transfer in public universities in Sichuan Province, the pilot universities, as the main body to carry out the reform of on-duty invention ownership, will be allowed to freely transfer their on-duty inventions.

\subsubsection{Comparative analysis of the development of university patents}

To further analyze the impact of the 2016 pilot reform on universities, this article divided samples into

\footnotetext{
${ }^{2}$ In this article, "patent transfer" refers to patent transfer and licensing.

${ }^{3}$ In 2016, the pilot universities of the Mixed Ownership Reform of On-duty Invention Ownership in Sichuan Province Pilot Implementation Plan involves Sichuan University, Southwest Jiaotong University, Sichuan Agricultural University, Chengdu University of Traditional Chinese Medicine, Southwest University of Science and Technology, Chengdu University of Technology, Chengdu University of Information Technology (College), Chengdu University (College), Sichuan University of Technology, Panzhihua College.
} 
two groups, namely reform pilot group and control group. The members of the pilot group participated in the 2016 ownership reform, while the control group did not. Due to the large gap in the number of patents between public universities in Sichuan Province, based on the patent data of each university in the past ten years, the top 10 ranked by the number of patent publications were selected into the two groups ${ }^{4}$ as analysis samples. The time range of this research on the patents of the pilot group and the control group is 2008-2018 (covering the 2016 reform year and including the longer data observations before that). The year 2008 is the first year for China to implement the national intellectual property strategy. In this research, the data scope covers the "preparation period" (2008-2015) and "start-up period" (after 2016) of the reform policy, and the time cycle from 2008 to 2018 is collectively referred to as the complete "policy cycle". A total of 50,031 pieces of patent data of the two groups universities were retrieved, and 47,330 pieces of data obtained by filtering industrial designs. The Figure 5 and Figure 6 reflect the comparison of patent disclosure and transfer trends in universities in the province.
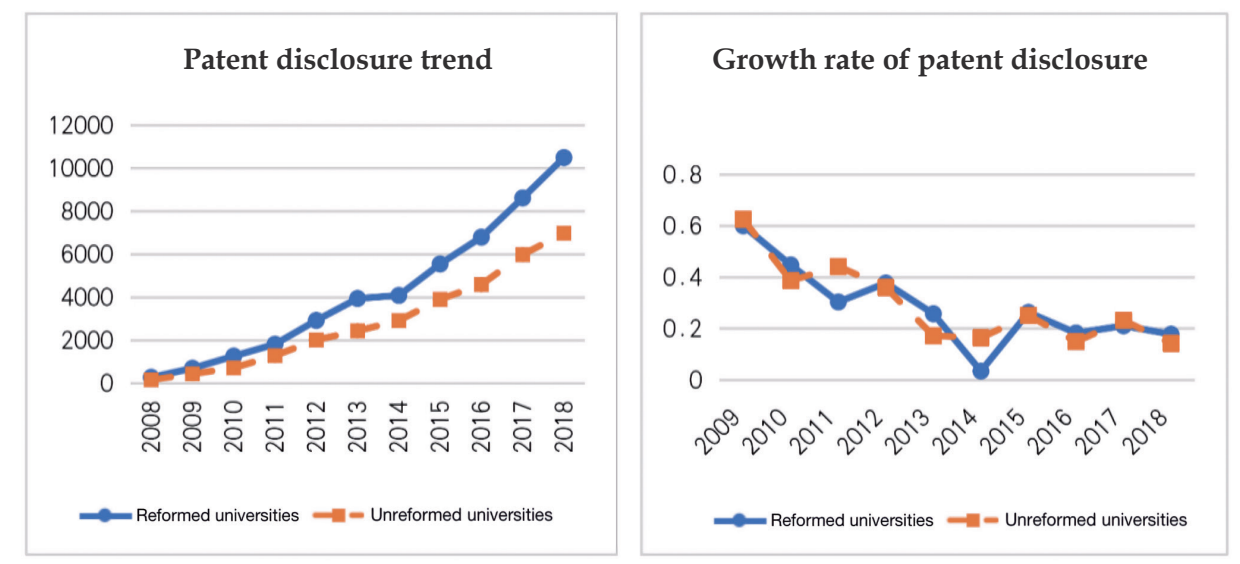

Fig. 5 The trend of patent disclosures between universities that did and didn't pilot the reform
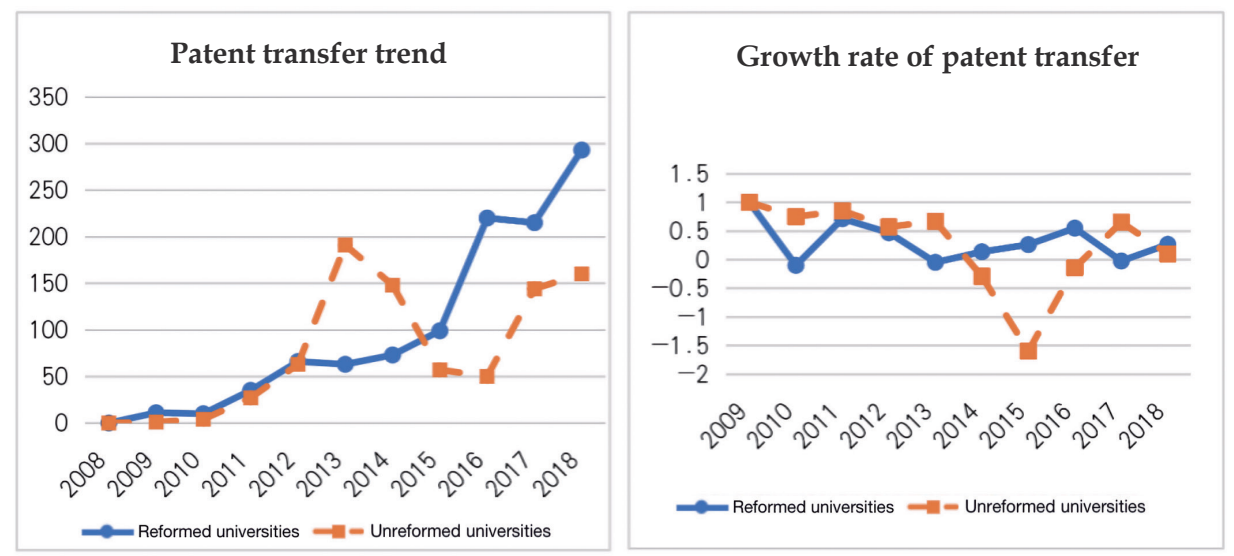

Fig. 6 The trend of patent transfer between universities that did and didn't pilot the reform

\footnotetext{
${ }^{4}$ The control group includes the ten universities with the largest number of patents in ten years, namely: University of Electronic Science and Technology, Southwest Petroleum University, Xihua University, Sichuan Normal University, Leshan Teachers College, Southwest University for Nationalities, Chengdu Institute of Technology, Xichang College, Xihua Normal University, Neijiang Teachers College.
} 
Data shows that since 2008, the number of patent related achievements disclosed and transferred in universities in Sichuan Province has continued to increase. Although the total number has been rising year by year, but its growth rate has been declining every year. In terms of the number of disclosures, the trend of the pilot group and the control group was generally consistent. However, in terms of the number of patent transfer, the pilot group and the control group showed a great difference or even opposite trend in the recent five years. From the perspective of quantity, before 2012, the trend of patent transfer between the two groups was generally consistent, and the number of patent transfers was relatively close. From 2012 to 2017, the transfer trend of the two groups was in sharp contrast with that of 2015. Before 2015, the number of patent transfer in the pilot group was much lower than that in the control group. In 2015, the number gap between the two groups narrowed. From 2016 to 2017, the number of patent transfer in the pilot group far exceeded that of the control group. Subsequently, it showed a parallel trend of growth in 2017 and 2018. From the perspective of growth rate, the growth trend of the two groups was essentially parallel before 2015, but a diverge point appeared in 2016 and the nodes converged in 2018. From 2015 to 2018, there have been some variations in patent transfer in universities in Sichuan Province.

Based on the differences between the two groups of universities, the pilot universities have a sensitive response to the policy intervention of Sichuan Province's on-duty invention ownership reform in 2016, and the patent transfer growth of Sichuan province's occurred around 2016, which is basically consistent with the time of the promotion of on-duty invention ownership reform. So, hypothesis 1 is supported. The reason for the "V" pattern reversal in the number of patent transfers in the control group from 2013 to 2017 remains to be further explored.

\subsection{Patent quality analysis}

To further study the development of patents in universities from the perspective of the reform policy impact in Sichuan province, and to explore the influence of the reform on patent quality in universities, some representative patent indexes are selected ${ }^{5}$ to preliminarily evaluate and analyze the patent quality of the universities, in order to draw out the comprehensive effect of the reform.

\subsubsection{Comparison of overall quality of invention patents}

a. Patent quality evaluation index system

The quality of patents is often measured in three dimensions: technical, legal and economic, but the connotation of patent quality and patent value is different, the former is generally related to the level of technology, the strength of protection and the breadth of application fields, but the latter includes market and economic factors, covering technology, law, market, economy and other multiple factors. And the patent quality does not change due to the transfer and realization of economic value. The objective value of patented technology can be measured in its own quality, whether external acts such as transactions or judicial decisions occur. However, the subjective value of the patented technology depends on the game between the right holder and the counterpart, and the subjective value judgment of the patented

\footnotetext{
${ }^{5}$ In this paper, the analysis of patent quality is based on valid patent invention patents such as application, examination and grant, etc. The span of classification number and patent survival rate are calculated by the author's statistics. Among them, the patent life in Incopat database is used as the patent survival current for patents with expired rights, while the patent life of patents with expired rights is used as the patent survival current from the date of application to April 1, 2019, and the statistical month is used as the patent survival current.
} 
Table 1 Patent quality evaluation index system

\begin{tabular}{|c|c|c|c|c|c|}
\hline coding & dimension & coding & sub-dimension & evaluation index & explanation \\
\hline \multirow{4}{*}{ A } & \multirow{4}{*}{$\begin{array}{l}\text { Technical } \\
\text { dimensions }\end{array}$} & A1 & $\begin{array}{l}\text { Length of } \\
\text { technical } \\
\text { application }\end{array}$ & $\begin{array}{l}\text { Number of } \\
\text { references }\end{array}$ & $\begin{array}{l}\text { Total number of citations, } \\
\text { representing the degree of influence } \\
\text { on the patented technology }\end{array}$ \\
\hline & & A2 & $\begin{array}{l}\text { Breadth of } \\
\text { technology } \\
\text { application }\end{array}$ & $\begin{array}{l}\text { Span of } \\
\text { classification } \\
\text { number }\end{array}$ & $\begin{array}{l}\text { Classification number across } \\
\text { IPC classification, the longer the } \\
\text { span, the wider the application of } \\
\text { technology }\end{array}$ \\
\hline & & A3 & $\begin{array}{l}\text { Technology } \\
\text { maturity }\end{array}$ & $\begin{array}{l}\text { Instruction } \\
\text { page }\end{array}$ & $\begin{array}{l}\text { The more mature the patented } \\
\text { technology, the more detailed the } \\
\text { patent specification }\end{array}$ \\
\hline & & A4 & $\begin{array}{l}\text { Technical field } \\
\text { impact }\end{array}$ & $\begin{array}{l}\text { Patent family } \\
\text { number }\end{array}$ & $\begin{array}{l}\text { The number of patent family can } \\
\text { reflect the field and technical } \\
\text { influence of the patent to some } \\
\text { extent }\end{array}$ \\
\hline \multirow{2}{*}{ B } & \multirow{2}{*}{$\begin{array}{c}\text { Legal } \\
\text { dimensions }\end{array}$} & B1 & $\begin{array}{l}\text { Scope of Rights } \\
\text { protection }\end{array}$ & $\begin{array}{l}\text { Number of } \\
\text { claims }\end{array}$ & $\begin{array}{c}\text { The number of claims represents } \\
\text { the degree of comprehensiveness } \\
\text { of protection }\end{array}$ \\
\hline & & B2 & $\begin{array}{l}\text { Time protection } \\
\text { range }\end{array}$ & $\begin{array}{l}\text { The survival } \\
\text { time of patents }\end{array}$ & $\begin{array}{l}\text { The longer a patent license lasts, } \\
\text { the longer its protection will be }\end{array}$ \\
\hline
\end{tabular}

technology will greatly affect its transaction price. This paper only studies the corresponding indexes of technical and legal dimensions of patent quality selection based on technical advancement and patent text writing quality. As shown in Table 1.

b. Patent quality before and after the pilot reform

In line with the existing patent quality measurement method, the extreme value method and the efficacy coefficient method were used for dimensionless treatment. In the process of data analysis, considering the time lag between patent application and patent grant, and significant deviation occurred when patent lifecycle was brought into the analysis results, so the study eliminated the patent survival index, and used classification number span, manual pages, the number of patent kin, the number of claims in the measuring system.

c. Data processing results

This paper equalizes the indicators, adopt $\frac{X \mathrm{Xij}-X \min }{X \max -X \min }$ range standardization, the difference in the data is retained, and the collected patent index data is linearly transformed to realize dimensionless. Thus to make the results fall within the range of, and take the average value as the comprehensive score of each patent to obtain the status of patent quality of 20 universities in Sichuan province from 2008 to 2018 as follows (as shown in Figure 7).

As shown in Figure 7, from the perspective of measurement and statistics, the variation and difference of patent quality in the universities are not obvious, so hypothesis 2 is not significantly supported. Over the past decade, the quality of university invention patents in Sichuan has risen slowly, compared with the growth in quantity. How the mixed ownership reform of on-duty invention ownership has affected the change of patent quality in universities remains to be further tested. 
The quality of invention patent in the universities in Sichuan province based on extremum method

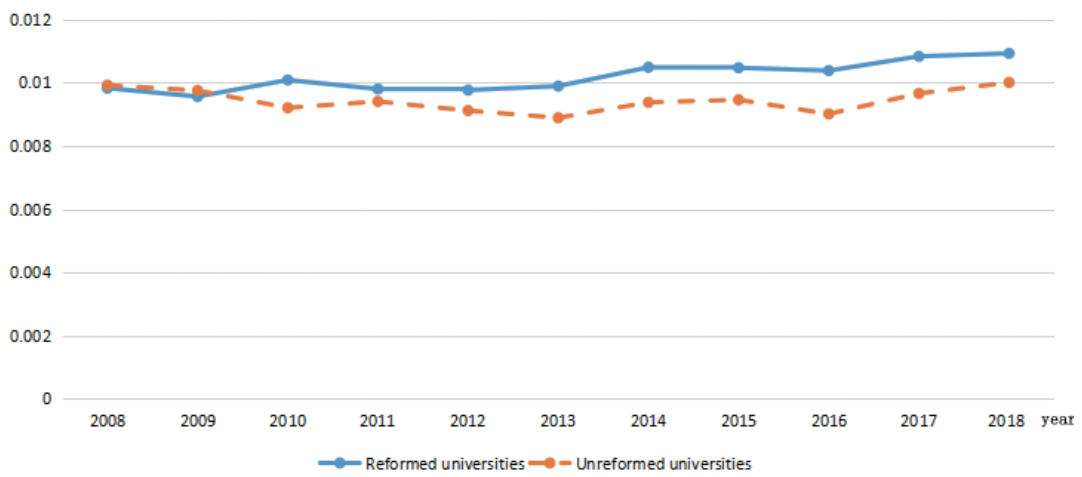

Fig. 7 Patent quality comparison between the reformed and unreformed universities in Sichuan Province

\subsubsection{Inter-universities comparison of quantity and quality of invention patents}

In order to further investigate the quality of invention patents in the 20 universities, the quantity and quality of effective invention patents were analyzed:

a. Quantitative trend comparison

The number of valid invention patents varies greatly among universities in Sichuan, and the innovation strength of universities varies greatly among different regions. University of Electronic Science and Technology ranks first in the number of valid invention patents, which was followed by Sichuan University and Southwest Jiaotong University. In addition, data shows that the number of patents in universities has increased rapidly since 2012.

b. Quality trend comparison

The patent quality of universities in Sichuan varied slightly among universities, but there was no significant difference. To further compare the differences in the patent quality situation between universities, as the harmonic curve can form the curve by fitting the quality of each university at different time points and can better reflect the distribution degree of patent quality in universities, the study compared the stability and consistency of patent quality between reformed and unreformed universities by using the harmonic graph to analyze the universities in the pilot group and the control group respectively (as shown in Figure 8).
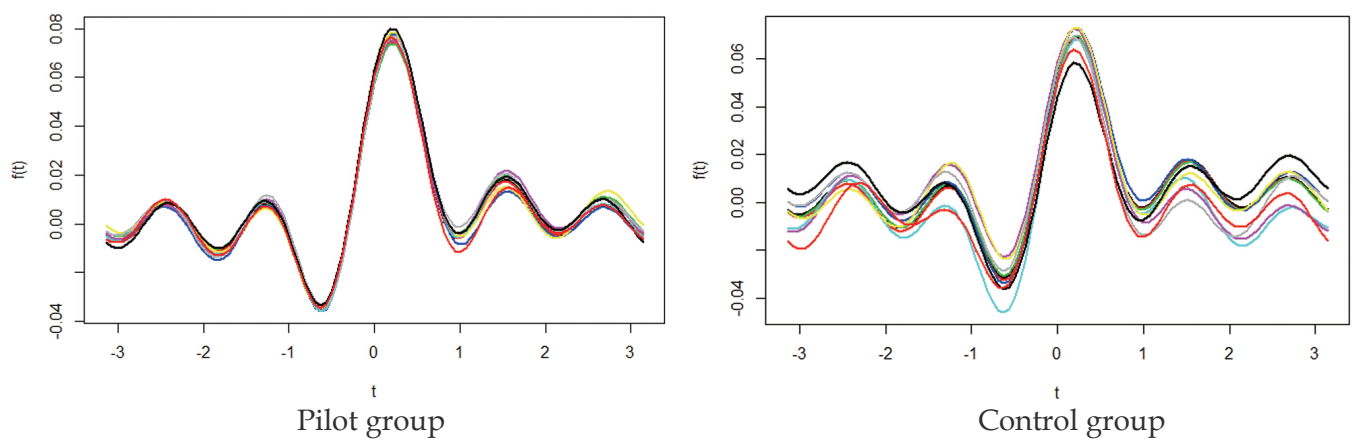

Fig. 8 Harmonic curve of universities in the pilot group and control group from 2008 to 2018 
The Figure 8 shows that the overall level of universities in the pilot and control groups is somewhat different: the patent quality of universities in the pilot group is relatively stable and consistent, while those in the control group is somewhat dispersed, which reflects that the pilot universities have obvious advantages over the non-pilot universities in terms of patent quality stability. Among the universities in the control group, the patent quality of public universities with fewer invention patents fluctuated greatly each year. Included in the analysis of the types of universities and the analysis of the actual situation of universities clustering effect, this paper holds that the universities in Sichuan province are different in patent quality control level, although overall patent quality did not show significant variation, but the universities have quite different patent quality management level, especially the patent fluctuation of universities with less innovation resources and fewer patents is more obvious.

\section{A Case Study of Patent Development in Southwest Jiaotong University}

Known as the "Xiaogang Village" (a village considered lighting the torch for China's land reform in 1978) for the reform of the ownership of on-duty inventions, Southwest Jiaotong University is the first one in China to pilot the exploration, which has attracted wide attention from all sides. In order to deeply analyze the effect and influence mechanism of mixed ownership reform of on-duty inventions on campus, which was started sporadically in 2010, Southwest Jiaotong University was taken as a typical case of jobrelated scientific and technological invention ownership reform in Sichuan Province in 2016, and the development status of patent quantity and quality in recent ten years is investigated.

\subsection{Development of quantity and quality of patents of Southwest Jiaotong University}

a. Trend of patent quantity development

In addition to the increasing number of patent applications year by year, the proportion of invention patent applications in Southwest Jiaotong University reached the peak in 2017, and the structural optimization was evident. Meanwhile, the patent expiration rate after the pilot reform dropped significantly, close to 0 (as shown in Figure 9).

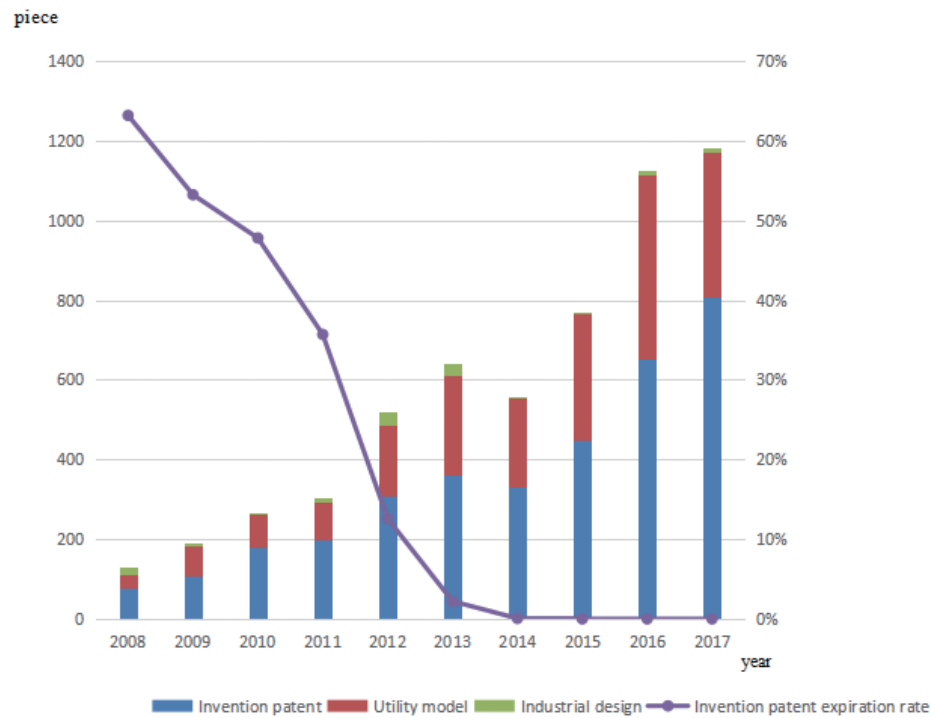

Fig. 9 Changes of patent structure and expiration rate in the past decade in Southwest Jiaotong University 


\section{b. Patent quality development trend}

Based on the preceding data and methods of patent quality comparison between universities, the variation of patent quality of Southwest Jiaotong University is presented in this part. From 2008 to now, the number of patent applications and disclosures of Southwest Jiaotong University has continued to increase, which is basically consistent with the overall development trend of Sichuan Province. In the past ten years, the development trend of patent quality in Southwest Jiaotong University has been rising circuitously. In 2009, 2013 and 2017, the patent quality increased respectively (as shown in Figure 10).

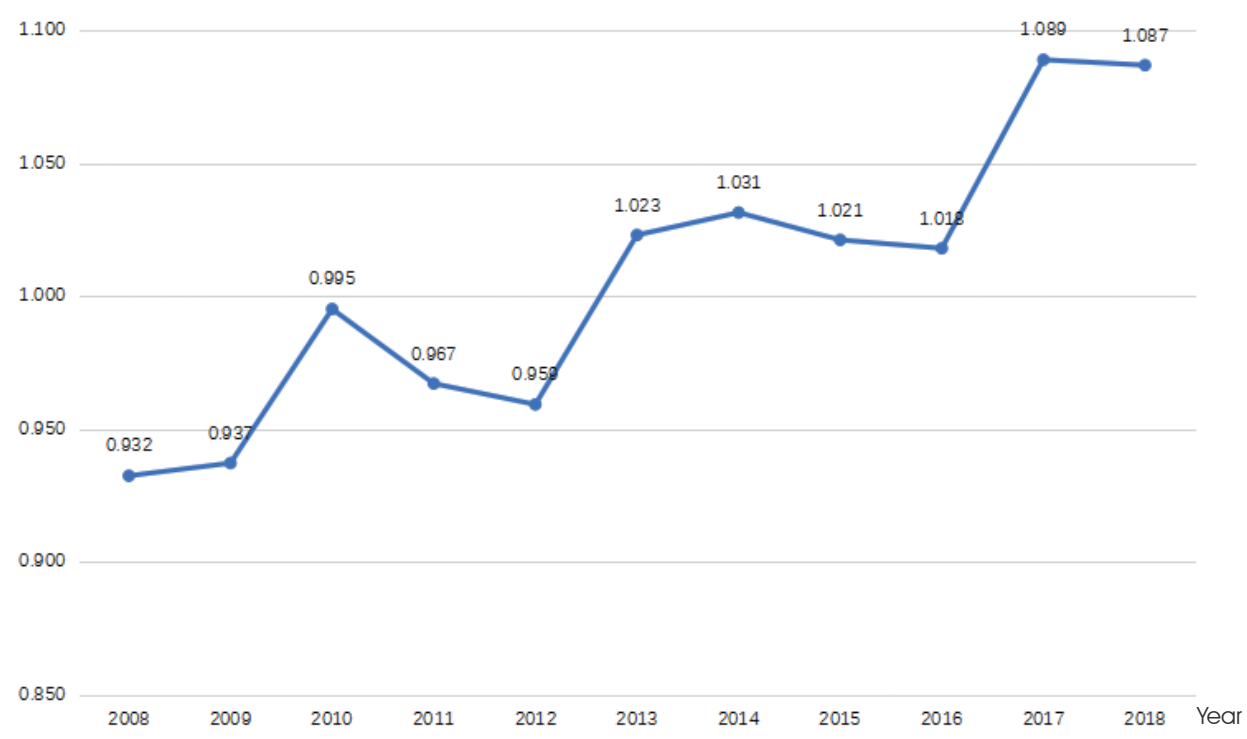

Fig. 10 Variation of patent quality in Southwest Jiaotong University

\subsection{Transfer practice of job-related on-duty inventions of Southwest Jiaotong University}

a. Transfer mechanism of job-related on-duty inventions

A community of on-duty inventions transfer mainly composed of inventors, universities, incubators and enterprises is taking shape in Sichuan Province, and is producing certain demonstration effect after incubation and transfer. In the process of promoting the mixed ownership of job-related on-duty inventions in universities, Southwest Jiaotong University and other universities that have carried out the pilot reform are committed to improving the supporting mechanism for the transfer of job-related on-duty inventions on campus. This process will promote the incubation and transfer of on-duty inventions in universities in Sichuan as a whole to form a system. So take Southwest Jiaotong University as an example. Since its independent exploration in 2010, the university officially launched the mixed ownership reform of scientific and technological inventions in employment in 2016. It has gradually explored a set of transfer mechanisms for achievements and technology investment, and has been exerting an important influence both inside and outside Sichuan.

b. Transfer effect of job-related on-duty inventions

From 2010 to 2015, before the formal policy was issued, Southwest Jiaotong University had 14 patent transfers and licensed on-duty inventions, with an income of 1.58 million yuan. After the promulgation of the New Law on The Transfer of On-duty Inventions in 2015 and the implementation of the "Nine Articles of Southwest Jiaotong University" in January 2016, the number of transfer of Southwest Jiaotong University 
has soared. It is worth noting that 2016 was the peak period for the change of intellectual property rights in Southwest Jiaotong University, and then fell sharply. On the one hand, it shows that the policy has a significant effect on the transfer of the university's on-duty inventions. On the other hand, it indicates that on-duty inventions entered the stage of transfer and incubation after the change of intellectual property rights. As of February 2019, the university has finished the establishment of intellectual property rights of 222 items, 185 of which are patents, and university and its employee inventors jointly applied for more than 20 on-duty invention patents. Through on-duty inventions made by segmentation, the university is shareholding registered 24 high-tech start-ups, with intellectual property assessment for equity totaling 130 million yuan, promoting social investment of nearly 800 million yuan. In contrast, from 2010 to 2015, Southwest Jiaotong University transferred and permitted 14 on-duty inventions, with a total income of 1.58 million yuan, and 9 million yuan of application fee, maintenance fee and patent bonus expenditure. A number of on-duty inventions of relatively high market value, such as cophase power supply, the 2th generation maglev, and new energy rail train (created by Southwest Jiaotong University), have been rapidly transformed. However, the low number of patent licenses is related to the barely satisfactory environment of technology market, the weak implementation of technology and the incomplete technical license regulations of schools. It is difficult to objectively explore the effect of reform policies only from the statistical perspective, and it needs to be further verified by quantitative policy evaluation.

\section{Conclusion}

Through the examination and case analysis of 2008-2018 Patent Database, it is found that after the implementation of the Reform, the number of disclosures of university on-duty invention patents increases rapidly, and the patent transfer in universities changes actively, but the variation and difference of patent quality among universities are still quite obvious. Hypothesis 1 is partially verified, while hypothesis 2 is not. Based on the current institutional circumstance, this paper provides Chinese experience and data analysis on the influence of intellectual property ownership structure on patent output.

In the past ten years, the number of invention patent applications in universities in Sichuan has increased, but the quality improvement of university patents has been slow. The field of scientific and technological innovation continues to develop and expand. However, the invention patent grants of universities in Sichuan still maintain the same level as five years ago. The patent quality of current universities in Sichuan as a whole is generally not high, but the patent quality of universities under reform is obviously improved, and "garbage patent bubble crowding out effect" appears. The overall patent structure of the sample universities is fine, and the advantages of university innovation gradually emerge. University patents mainly concentrate on invention patents, and its distribution is rather reasonable. Under the mixed ownership reform of on-duty inventions, the patent transfer activities in universities are increasing year by year. In the context of more stringent patent examination system, the number of patent applications in Sichuan province may decrease, while the promotion of mixed ownership reform of on-duty inventions in Sichuan province will further promote the transfer and development of existing patents, and the invention disclosure is expected to rise. There are obvious differences in innovation foundation and ability as well as patent quality control among universities. Individual differences should be concerned continuously to promote the mixed ownership of job-related on-duty inventions. The number of patents in universities varies greatly, as a whole, the innovation strength of the Education 
Ministry affiliated universities is much higher than that of the local universities. The results of the current mixed ownership reform of job-related scientific and technological achievements will take the lead in the universities affiliated to the Ministry and some provincial universities with large number of patents and strong innovation strength, this part of colleges and universities that are likely to realize the incubation and transformation of post scientific and technological achievements will play a major role in the process of innovation and development.

Based on the above findings, from the perspective of public policy, it is necessary to define the bottom line of "public property" and the path to realize the public interest in the privatization of some property rights of on-duty inventions in universities, so as to realize the balanced development of public interest and individual interest. The dynamic debugging policy and law need to be self-consistent, promoting the improvement of the 1.0 version of the pilot policy, and iterating its 2.0 and 3.0 versions, so as to build a systematic policy pilot. At present, laws and policies are promoting the "legitimacy" of mixed ownership reform of on-duty invention ownership in universities and institutes. In the future, the supporting implementation guidelines of the policies' "intermediate goal" should be strengthened, and be more observable, quantifiable and directly related to the starting point of the action.

\section{References}

Cao, A., Wang, H., Wang, Y., 2018. Research on Legal Ownership of Job-related On-duty Inventions. Science and Technology China, 5, 71-77.

Chen, B., Liu, Z., Zhan, Y., 2017. Reflections on Mixed Ownership of Job-related On-duty Inventions. Science and Technology of Chinese Universities, S2, 130-132.

Crespi, G., Geuna, A., Nomaler, O., et al., 2010. University IPRs and knowledge transfer: is university ownership more efficient?. Economics of Innovation \& New Technology, 19, 627-648.

Ejermo, O., Källström, J., 2016. What is the causal effect of R\&D on patenting activity in a "professor's privilege" country? Evidence from Sweden. Small Business Economics, 47, 677-694.

Geuna, A., Rossi, F., 2011. Changes to university IPR regulations in Europe and the impact on academic patenting. Research Policy, 40, 1068-1076.

Halilem, N., Amara, N., Julia, O., et al., 2017. “To Own, or not to Own?” A multilevel analysis of intellectual property right policies' on academic entrepreneurship. Research Policy, 46, 1479-1489.

Hans, K. H., Benjamin, F. J., 2018. University innovation and the professor's privilege. American Economic Review, 108, 1860-1898.

Han, X., Li, M., 2016. Reflections on Some Issues Concerning the Construction of Intellectual Property Power. Management World, 5, 1-8.

Kenney, M., Patton, D., 2011. Does inventor ownership encourage university research derived entrepreneurship? A six university comparison. Research Policy, 40, 1100-1112.

Lissoni, F., Montobbio, F., Seri, R., 2010. Ownership and impact of European university patents. EAEPE Conference, 28-30.

Liu, X., et al. 2019. Mixed ownership of employee inventions in China's universities: progress, issues and suggestions. Queen Mary Journal of Intellectual Property, 9: 42-60

Ma, T., 2018. High-value Patent Screening. Beijing, Intellectual Property Press.

Siegel, D. S., Veugelers, R., Wright, M., 2007. Technology transfer offices and commercialization of university intellectual property: performance and policy implications. Oxford Review of Economic Policy, 23, 640-660.

Wu, S., 2017. Analysis of Hot Issues of Transfer of On-duty Inventions (III) - Talk again about mixed ownership of On-duty inventions. Science and Technology China, 8, 30-33.

Xia, H., 2007. Research on the Development of Property Rights Theory and the Construction of Property Rights System. Jilin University, 8-15.

Zhang, J., Yuan, X., 2014. Does China's “Baidu Rule" promote the patent output of universities? Research in Science of Science, 32, 1859-1866+1887. 